\title{
Factorial Analysis of Self-Monitoring on Emotional Intelligence among Retail Stock Market Investors
}

\author{
BIJU THOMAS MUTTATH \\ Research Scholar, Bharathiar University, Coimbatore - 641046 \\ General Manager, Star Group of Companies \\ Kanjany Road, Thrissur - 680 003, Kerala, South India \\ Email: btmuttath@gmail.com \\ Tel: +919446337474 \\ Dr. ASSISSI MENACHERY \\ Vice President (Quality Assurance) \\ QMPG Industrial \& Certification Services \\ C.C 48/1307, Poonithura P.O, Kochi, Kerala, India - 682038 \\ Advisor \& Professor (Institute Industry Interface) \\ Loyola Institute of Technology \& Science \\ Thovalai Post - 629 302, Kanyakumari Dist. Tamilnadu \\ Email: f11assissim@iima.ac.in \\ Tel: +91 9388555554
}

\begin{abstract}
Self-monitoring refers to the ability to regulate behaviour to accommodate social situations. Individuals high on self-monitoring are highly responsive to social cues and can behave differently in different situations. Low self- monitors are more likely to control expressive behaviours incongruent with their own beliefs, attitudes and dispositions regardless of social situations. Emotional intelligence is the ability to be aware of and use emotions productively for reasoning and problem-solving. Those who are high on emotional intelligence are able to use and integrate their moods and emotions effectively. Researches in the Indian context, on self-monitoring and emotional intelligence among the retail stock market investors, are scarce. The objective of the study is to examine the relationship between self-monitoring and emotional intelligence dimensions. This study analyses the similarities and differences that self-monitoring and emotional intelligence could impose on short-term and long-term stock market investors. Moreover, the impact of 'levels of self-monitoring' on emotional intelligence dimensions is analyzed and discussed. It is hypothesized that the retail stock market investors investing in a short term and long term orientation and their low and high self-monitoring levels would remain to be homogenous on their emotional intelligence scores. Short-term and long-term investors and the levels of self-monitoring failed to differentiate on the emotional Intelligence competence of the investors. The short term and long term investors and the levels of self-monitoring differ on all five dimensions of the emotional intelligence scale.
\end{abstract}

Keywords: Emotional Intelligence, Self-monitoring, Short \& Long Term Investing.

\section{Introduction}

Self-monitoring refers to the ability to regulate behaviour to accommodate social situations and adjust to external, situational factors (Robbins \& Timothy, 2009). Individuals high on self-monitoring are highly responsive to social cues and can behave differently in different situations. It is presumed that high selfmonitors will be better opportunity seekers and they will succeed in almost all their endeavours. Low selfmonitors are more likely to control expressive behaviours incongruent with their own beliefs, attitudes and 
dispositions regardless of social situations. Emotional intelligence refers to the capacity for recognizing one's own feeling and those of others, for motivating others, motivating ourselves and for managing emotions well in one-selves and in relationships (Goleman, 1998). Individuals who are high on emotional intelligence can use and integrate their moods and emotions effectively. However, those with low emotional intelligence may misinterpret, ignore, or be overwhelmed by their emotions and moods and thus potential benefits may not be reaped (Salovey \& Mayer, 1990). In stock market investing the gains and losses are normal parts of the economic cycle. However, it is noted that most investors do not respond equally to gains and losses. However, it is reported that investors undergo positive emotions when they gain profits whereas go through relatively stronger negative emotions from a realized loss of the same size (Kahneman \& Tversky, 1973: 1979).

Short-term investors invest in a stock to a maximum of one year whereas long-term investors invest more than one-year time span. Short-term investor's trade when the market is low and sell before one year, but they incur more transaction costs. The main benefits of short-term investment are the potential for fast growth and the fact that the term may only last a few weeks to a few months. These investments tend to be riskier and show a much higher rate of fluctuation than long-term investments. On the contrary, long-term investors look at the long-term prospects of the company rather than watching little fluctuations in the market. Long-term investors seek out dividend-paying companies that have proven track record of stability and growth. Long-term investments have the ability to gain small amounts of money over a longer period of time. The slow but steady pace of long-term investments allows for a much greater degree of stability and a much lower risk than short-term investments.

The study on self-monitoring and emotional intelligence among the retail stock market investors in an Indian context is scarce. It is very true that dematerialization of the shares, advancement of communication technologies and its application in stock markets made the investors expand their investment horizons. Even though the opportunity to invest is similar and open to all investors, the investment objective may vary from individual to individual which directly correlates to their perceived risk. Perceived risk is the function of consequences and uncertainty (Cox \& Rich, 1964). Individuals frequently misperceive risk linked with a specific activity because they lack certain information. This misperception leads the individual to commit cognitive bias or mental mistakes or errors (Ricciadri, 2004; 2006). Thus, lack of relevant information and the possibility of perceived risk persuade the investors to discount the data that is predominantly influenced by psychological factors and personality traits enable them to make errors in investment decisions.

Self-monitoring is a personality construct and is an individual's ability to adjust ones' behaviour to environmental conditions. Individuals high on self-monitoring demonstrate adaptability in adjusting the behaviour to external situational factors. Thus, the trait self-monitoring seems to be potentially related to effective decision making in stock market investing, especially when investors respond quickly to the market news. The relationship between self-monitoring and its influence on investment decision making are yet to be empirically established. Even though there are few studies on self-monitoring ability and investment decisions, results of these studies have been inconsistent especially in case of male and female traders (Biais, Hilton, Mazurier \& Pouget, 2005). A recent study by authors revealed that high selfmonitors prefer to sell the stock within the shortest period of time responding to the minor changes in the market conditions whereas, low-self monitors tend to hold the stock for longer periods without responding to the changes in the stock markets (Biju \& Menachery, 2018).

Similarly, emotional intelligence is the ability to perceive emotions of one's own and that of others, to discriminate and to use this emotional information to guide thinking and behaviour. House-money effect, herd behaviour, thought contagion, overreaction etc., are some of the perils that could unwittingly influence the emotional behaviour of the individuals. An individual's tendency to take high risk under the influence of recent gains is termed as House-money effect (Thaler \& Johnson, 1990). Herd behaviour of the individual explains the individual's tendency to rationally or irrationally mimic the actions of the large 
group, which they may desist from doing as individual (Olsen 2010; Thomas 1995). The pressure from society for conformity and common rationale that large groups cannot be wrong are the two determinants of herd behaviour. Thought contagion is self-spreading mass belief that gains widespread receptivity and prevalence, irrespective of its accuracy or usefulness (Lynch, 2002). Overreaction is the disproportionate reaction to news in the market. Overreaction could lead to over pricing from winner or even vice versa (De Bondt \& Thaler, 1985). However, the number of research studies on the emotional intelligence of the individual with respect to investment in the financial market is limited and evidence are inconclusive (Ameriks, Wranik \& Salovey, 2009). Further, research provides evidence that investors who are high in emotional intelligence are often underexposed in equities rather than index-based funds, and found no systematic relationship between emotional intelligence and return. Effect of individuals' emotional intelligence on investment behaviour is yet to be empirically established. However, a recent study by authors conducted in India demonstrated that Investors with high levels of emotional intelligence have long-term investment orientation and low levels of emotional intelligence have short-term investment orientations (Biju \& Menachery, 2018).

The above discussions confirm that stock market investing is potentially related to emotional intelligence and self-monitoring. This conclusively affirms that self-monitoring and emotional intelligence might have an influential relationship to investor behaviour and their investment decisions. These variables could be applied to derive outcomes whose practical usefulness may be positively magnified across the investment avenues. As behavioural factors have prominent influence in real life situations of individuals, these factors will have an influential role in decision making where expected return may volte-face due to the uncertainties in the stock market. Thus, behavioural finance draws heavily from psychology which explains human beings behave in various situations. Self-monitoring and emotional intelligence are those psychological constructs that may have a prominent role in the decision-making process and hence this study.

\section{Objectives of the Study}

The study aims to observe and analyse the differences or similarities among self-monitoring, and emotional intelligence among active stock market investors with respect to their investment orientations (short term and long term). The main objectives are:

1) To study the self-monitoring characteristics of individual investors on short-term and long-term investment orientation.

2) To study the impact of levels of self-monitoring on various emotional Intelligence dimensions.

3) To study the similarities or differences with a special focus on the dimensions of emotional intelligence among the active stock market investors with respect to short-term and long-term investment orientations.

\section{Materials and Methods}

In order to measure self-monitoring, the self-monitoring scale developed and revised by Lennox and Wolfe (1984) was used. Thirteen Likert-type scale questions were distributed that need to be responded to a fourpoint rating scale starting from 'always true', 'sometimes true', 'sometimes false' and 'always false'. The minimum possible score is 13 and maximum is 52 . Eleven questions are to be scored by the direct method and 2 items are to be scored by the reverse method. Lower scores relate to low levels of self-monitoring and high scores relate to high scores of self-monitoring.

The scale developed by Reuven Bar-On (1997), called Bar-On 'E.Q-i', to measure Emotional Intelligence was used. It comprises ' 133 ' items and employs five-point response ranging from "not true of me" to "true of me", measuring the five composite factors which include fifteen sub-scales namely Emotional selfawareness, assertiveness, self-regard, self-actualization, independence, empathy, interpersonal relationship, 
social responsibility, Problem Solving, reality testing, flexibility, stress tolerance, impulse control, happiness and optimism. Of the ' 133 ' items, sixty-one items were scored in the reverse direction. Of the total number of items, as many as ' 117 ' items were taken for calculation purpose.

For the purpose of the study, retail investors investing in the broking houses approved by SEBI in Kerala state were marked as the Universe. On perusal of the records at Security Exchange Board of India (SEBI) resulted in 36 broking houses having an office in Kerala state form the universe. From the Universe, three districts, 'Ernakulum', 'Malappuram' and 'Thrissur', were chosen as sampling units through lottery method from among the fourteen districts of Kerala. Permission was requested to conduct the study in all the above-said broking institutions from four districts. 'Five' institutions responded positively to provide the client list. 'Forty-six' branches of these institutions at four districts were categorized alphabetically and numbered numerically as per the alphabetical order of the places. Further one branch from every three was selected using systematic random sampling. The client list of 'fifteen' branch offices was formed as the sampling frame. Further, all individual investors from 'fifteen' branch offices categorized alphabetically and numbered numerically as per the alphabetical order comprising 'six hundred and forty-nine' retail investors. One investor from every two, based on the numerical numbering was selected for the study comprising of 'three hundred twenty-four retail investors' as a sample.

The response sheets which explain the purpose and scope were initially sent to all respondents. After three weeks the respondents were reminded and requested to complete the response sheets filled and send back. Many respondents completed the questionnaire and sent it back. The researcher visited personally to the residents of respondents and collected the completed response sheets from those who could not respond in time. Totally 'three hundred and sixteen' retail investors were responded among them 'twenty-eight' questionnaires were rejected as responses were not complete. Finally, a total number of retail investors considered as the sample was "two hundred eighty-eight".

\section{Theoretical Framework}

\section{Classification of the respondents based on their scores on Self-Monitoring}

Based on the levels of self-monitoring the respondents are classified as high and low. For the purpose of classification, the scores on the self-monitoring scale are arranged in an ascending order. Further, the respondent's theoretical mean (median) scores are divided into two groups. Those respondents who scored above the median score are categorized as high self-monitors. On the contrary, the respondents who scored less than the median score are classified as low self-monitors. The median score is removed from further analysis. Finally, ' 157 ' investors found to be high-self monitors and ' 131 ' investors are low self-monitors.

Table 1: Classification of High-Low self-monitoring

\begin{tabular}{|c|c|c|c|c|c|c|c|}
\hline \multirow{2}{*}{$\begin{array}{c}\text { S1. } \\
\text { No }\end{array}$} & \multirow{2}{*}{$\begin{array}{c}\text { Self } \\
\text { Monitoring }\end{array}$} & \multicolumn{3}{|c|}{ Short term } & \multicolumn{2}{|c|}{ Long-term } & \multicolumn{2}{|c|}{ Total } \\
\cline { 3 - 8 } & $\mathrm{N}$ & $\%$ & $\mathrm{~N}$ & $\%$ & $\mathrm{~N}$ & $\%$ \\
\hline 1 & $\begin{array}{c}\text { High Self } \\
\text { Monitors }\end{array}$ & 119 & 41.3 & 38 & 13.2 & 157 & $\mathbf{5 4 . 5}$ \\
\hline 2 & $\begin{array}{l}\text { Low Self } \\
\text { Monitors }\end{array}$ & 49 & 17.0 & 82 & 28.5 & 131 & $\mathbf{4 5 . 5}$ \\
\hline & Total & $\mathbf{1 6 8}$ & $\mathbf{5 8 . 3}$ & $\mathbf{1 2 0}$ & $\mathbf{4 1 . 7}$ & $\mathbf{2 8 8}$ & $\mathbf{1 0 0}$ \\
\hline
\end{tabular}

The proposed conceptual model has been shown in figure 1. This two way ANOVA observe and analyse the similarities or differences among self-monitoring and emotional intelligence among retail investors with respect to their investment orientations (short term and long term). 


\section{Proposed Conceptual Model}

Factorial analysis of Self-Monitoring on Emotional Intelligence

\begin{tabular}{|c|c|c|}
\cline { 2 - 3 } \multicolumn{1}{c|}{} & $\begin{array}{c}\text { Short-term } \\
\text { Investors }\end{array}$ & $\begin{array}{c}\text { Long-term } \\
\text { Investors }\end{array}$ \\
\hline $\begin{array}{c}\text { Helf-monitoring } \\
\text { Self }\end{array}$ & $\begin{array}{c}\text { Emotional } \\
\text { Intelligence } \\
\text { Dimensions }\end{array}$ & $\begin{array}{c}\text { Emotional Intelligence } \\
\text { Dimensions }\end{array}$ \\
\hline Low monitoring & $\begin{array}{c}\text { Emotional } \\
\text { Intelligence } \\
\text { Dimensions }\end{array}$ & \\
\hline
\end{tabular}

Figure 1: Analysis of Covariance

\section{Hypotheses}

The respondents belonging to the categories of individual investors (criterion groups) of different investment orientations (short-term and long-term) and the low and high self-monitoring levels would remain to be homogenous on their scores on emotional intelligence sub-scales viz.
(1) Intrapersonal
(2) Interpersonal
(3) Adaptability

\section{(4) Stress Management and (5) General Mood}

Based on the above hypotheses, detailed hypotheses could be advanced as follows:

3.1.1 (a) The respondents investing in the short term and long term would remain to be homogenous on their scores on the 'intrapersonal' sub-scale of the emotional intelligence scale.

(b) The respondents with low and high self-monitoring levels would remain to be homogenous on their scores on the 'intrapersonal' sub-scale of the emotional intelligence scale.

(c) The respondents investing in the short term and long term and the low and high self-monitoring levels would remain to be homogeneous on the scores of 'intrapersonal' sub-scale of the emotional intelligence scale.

3.1.2 (a) The respondents investing in the short term and long term would remain to be homogenous on their scores on the 'interpersonal' sub-scale of the emotional intelligence scale.

(b) The respondents with low and high self-monitoring levels would remain to be homogenous on their scores on the 'interpersonal' sub-scale of the emotional intelligence scale.

(c) The respondents investing in the short term and long term and the low and high self-monitoring levels would remain to be homogeneous on the scores of 'interpersonal'sub-scale of the emotional intelligence scale.

3.1 .3 (a) The respondents investing in the short term and long term would remain to be homogenous on their scores on the 'adaptability' sub-scale of the emotional intelligence scale.

(b) The respondents with low and high self-monitoring levels would remain to be homogenous on their scores on the 'adaptability' sub-scale of the emotional intelligence scale.

(c) The respondents investing in the short term and long term and the low and high self-monitoring levels would remain to be homogeneous on the scores of 'adaptability' sub-scale of the emotional intelligence scale. 
3.1.4 (a) The respondents investing in the short term and long term would remain to be homogenous on their scores on the 'stress management' sub-scale of the emotional intelligence scale.

(b) The respondents with low and high self-monitoring levels would remain to be homogenous on their scores on the 'stress management' sub-scale of the emotional intelligence scale.

(c) The respondents investing in the short term and long term and the low and high self-monitoring levels would remain to be homogeneous on the scores of 'stress management' sub-scale of the emotional intelligence scale.

3.1 .5 (a) The respondents investing in the short term and long term would remain to be homogenous on their scores on the 'general mood' sub-scale of the emotional intelligence scale.

(b) The respondents with low and high self-monitoring levels would remain to be homogenous on their scores on the 'general mood' sub-scale of the emotional intelligence scale.

(c) The respondents investing in the short term and long term and the low and high self-monitoring levels would remain to be homogeneous on the scores of 'general mood' sub-scale of the emotional intelligence scale.

\section{Results and Discussion}

The data collected are analysed using 2 X 2 ANOVA as described in figure 2. The study aims at observing and analysing the similarities or differences among self-monitoring and emotional intelligence among retail investors with respect to their investment orientations (short term and long term). Further, the study focused to find out the impact of levels of self-monitoring on various emotional intelligence dimensions. Moreover, the study also wants to find out the similarities or difference with a special focus on the dimensions of emotional intelligence among the retail investors with respect to short-term and long-term investment orientations and interactions if any. The results are analysed and discussed for the similarity or difference of the scores of the short term and long-term investors on the high and low levels of self-monitoring as well as interactions if any on five emotional Intelligence dimensions.

Table 2: Short term and Long-term Orientation V/s emotional intelligence dimensions

\begin{tabular}{|c|c|c|c|c|}
\hline \multirow{2}{*}{ Sub Scale } & \multicolumn{2}{|c|}{ Short Term } & \multicolumn{2}{c|}{ Long Term } \\
\cline { 2 - 5 } & Mean & SD & Mean & SD \\
\hline Intrapersonal & $151.42^{*}$ & 27.299 & 130.47 & 25.084 \\
\hline Interpersonal & $119.06^{*}$ & 13.433 & 93.80 & 19.081 \\
\hline Adaptability & $112.26^{*}$ & 11.004 & 96.59 & 11.147 \\
\hline Stress Management & $75.56^{*}$ & 9.717 & 71.92 & 8.352 \\
\hline General Mood & 70.43 & 11.310 & $76.67 *$ & 5.914 \\
\hline
\end{tabular}

* Higher mean score

From the above table it is inferred that the short term investors scored high on intrapersonal with mean score (151.42), interpersonal (119.06), adaptability (112.26) and stress management (75.56) dimension of emotional intelligence. On the contrary, the long-term investors scored high on general mood dimension (76.67) of the emotional intelligence scale.

\section{Long-term Investment Orientation, Self-Monitoring and Emotional Intelligence}

From Table 3, it is inferred that the long-term high self-monitors scored high on intrapersonal with mean score (49.05) and for general mood with mean score (77.05). On the contrary, long-term low self-monitors scored high on interpersonal(96.72), adaptability (98) and stress management (72.59) dimensions of the emotional intelligence scale. 
Table 3: Long-term orientation, self-monitoring and emotional intelligence

\begin{tabular}{|l|c|c|c|c|}
\hline \multirow{2}{*}{ Criterion Group } & \multicolumn{2}{|c|}{ Long-Term - High Self Monitors } & \multicolumn{2}{c|}{ Long-Term - Low Self Monitors } \\
\cline { 2 - 5 } Sub Scale & Mean & SD & Mean & SD \\
\hline Intrapersonal & $49.05^{*}$ & 16.484 & 21.87 & 23.735 \\
\hline Interpersonal & 87.50 & 23.539 & $96.72^{*}$ & 15.955 \\
\hline Adaptability & 93.55 & 14.324 & $98.00^{*}$ & 9.083 \\
\hline Stress Management & 70.47 & 8.110 & $72.59^{*}$ & 8.427 \\
\hline General Mood & $77.05^{*}$ & 5.991 & 76.49 & 5.907 \\
\hline
\end{tabular}

* Higher mean score

\section{Short-term Investment Orientation, Self-Monitoring and Emotional Intelligence}

From Table 4 it is inferred that the short - term high self-monitors scored high on intrapersonal with mean score (165.90), interpersonal (125.97), adaptability (117.76) and stress management (76.50) dimensions of the emotional intelligence scale. On the contrary, short-term low self-monitors scored high on general mood subscale of the emotional intelligence scale.

Table 4 Short Term Orientation, self-monitoring and Emotional Intelligence

\begin{tabular}{|l|c|c|c|c|}
\hline \multirow{2}{*}{ Criterion Group } & \multicolumn{3}{|l|}{ Short-term - High self-monitors } & \multicolumn{2}{l|}{ Short term - Low self-monitors } \\
\cline { 2 - 5 } Sub Scale & Mean & SD & Mean & SD \\
\hline Intrapersonal & $165.90^{*}$ & 11.556 & 116.24 & 21.946 \\
\hline Interpersonal & $125.97^{*}$ & 6.318 & 102.29 & 11.143 \\
\hline Adaptability & $117.76^{*}$ & 6.632 & 98.90 & 7.481 \\
\hline Stress Management & $76.50^{*}$ & 9.441 & 73.29 & 10.097 \\
\hline General Mood & 67.77 & 12.043 & $76.90^{*}$ & 5.320 \\
\hline
\end{tabular}

Table 5 Average mean score (Short-term and Long-term)

\begin{tabular}{|l|c|c|}
\hline \multicolumn{3}{|c|}{ Average Mean Score } \\
\hline Sub Scale & Mean & SD \\
\hline Intrapersonal & 142.69 & 28.311 \\
\hline Interpersonal & 108.53 & 20.287 \\
\hline Adaptability & 105.73 & 13.484 \\
\hline Stress Management & 74.04 & 9.333 \\
\hline General Mood & 73.03 & 9.920 \\
\hline
\end{tabular}

\section{Result and Discussion of ANOVA}

\section{Self - Monitoring, Investment Orientation and Emotional Intelligence}

The short term and long-term investors and the levels of self-monitoring failed to differentiate on all the dimensions of the emotional intelligence scale. As described in Table 7, at ' 0.05 ', significance level, all five subscales of emotional intelligence such as 'intrapersonal', 'interpersonal', 'adaptability', 'stress management' and 'general mood' remains the same irrespective of investment orientation, whether it is long term or short term.

Similarly, investors with high and low levels of self-monitoring failed to differentiate on four dimensions such as 'intrapersonal', 'interpersonal', 'adaptability', and 'general mood' dimension of the emotional intelligence scale. However, stress management dimension differed with respect to high and low levels of 
self-monitoring. On analysis, it is observed that investors, who are high self-monitors with short-term investment orientation, possess a high level of stress with a score (76.50). Moreover, there is no interaction on all five dimensions of emotional intelligence scale such as 'intrapersonal', 'interpersonal', 'adaptability', 'stress management' and 'general Mood'.

Table 6 Levels of Self - monitoring, Emotional Intelligence and Investment orientation

\begin{tabular}{|c|c|c|c|}
\hline Sub-scale & $\begin{array}{c}\text { Short-term and Long- } \\
\text { term investors }\end{array}$ & $\begin{array}{c}\text { Low and High } \\
\text { Self-Monitoring }\end{array}$ & Interaction \\
\hline Intrapersonal & 0.05 & 0.05 & 0.05 \\
\hline Interpersonal & 0.05 & 0.05 & 0.05 \\
\hline Adaptability & 0.05 & 0.05 & 0.05 \\
\hline Stress Management & 0.05 & $\mathrm{NS}$ & 0.05 \\
\hline General Mood & 0.05 & 0.05 & 0.05 \\
\hline
\end{tabular}

NS: Failed to achieve the statistical significance (Not Significant \& Homogenous) $\mathrm{P} \geq 0.05$ level of Significance.

\section{Conclusions}

The short-term investors are high on, intrapersonal, interpersonal, adaptability and stress management dimensions of the emotional intelligence scale. The long-term investors are high on general mood dimension of the emotional intelligence scale. While analysing the investment patterns together high selfmonitoring investors scored high on, intrapersonal, interpersonal, adaptability and stress management dimensions and low on general mood dimension of the emotional intelligence scale. However, when these parameters are analysed taking the investment patterns (long term and short term) individually, the results are different. It is likely that retail investors with investment patterns (short term and long term) would have different personality traits (self- monitoring) and emotional intelligence. It is aimed at studying the empirical relationship between personality (self-monitoring) and emotional intelligence on the investment patterns. From the analysis, it is possible to extricate the capabilities and skills that are unique for the highly complex scenario for investment at the international and national level. Stock market investing is highly risky and especially for short-term trading and investing. It is identified in the study that high selfmonitors go for short-term investments and trading. Those investors need to be aware of their personality traits such as self-monitoring and emotional intelligence. General awareness training programmes many given at a macro level to enhance awareness provided they are incurring losses in short-term investing. The investors high on self-monitoring are low on 'general mood' dimension of the emotional intelligence scale. General mood has got a lot of influence on taking decisions. If the general mood of an investor is inconsistent with respect to a minor market news it is likely that he may take a quick wrong decision on investing. Hence, leaders from the industry and government may conduct studies to identify the root cause for the lack of 'general mood' dimension. Adequate awareness programmes may be designed for the retail investors to fill the knowledge and competence gap.

\section{References}

Amos, Tversky. \& Daniel, Kahneman. (1973). Availability: A heuristic for judging frequency and probability, Cognitive Psychology, 5, 207-232.

Biju, Thomas Muttath., \& Assissi, Menachery. (2018). Impact of emotional intelligence on investment decision, Journal of Management Decision and Analysis, 5(1), 255-260.

Biju, \& Menachery. (2018). Impact of self-monitoring on investment periods: An empirical analysis, International Research Journal of Management and Commerce, 5(3), 458-465.

Biais, B., Hilton, D., Mazurier, K., \& Pouget, S. (2005). Judgemental overconfidence, self-monitoring, and trading performance in an experimental financial market. The Review of economic studies, 72(2), 287312. 
Cox, D.F. \& Rich, S.V. (1964).Perceived risk and consumer decision making - The case of telephone shopping, Journal of Marketing Research, 1, 32-39.

Daniel, Kahneman. \& Amos, Tversky. (1979). Prospect theory: An analysis of decision under risk, Econometrica, 47(2), 263-291.

De Bondt, Werner.,\& Thaler, R. (1985). Does stock market overreact? Journal of Finance, 40, 793-808.

Goleman, Daniel. (1998). The emotional intelligence of leaders, Frances Hesselbein Leadership Forum, 1998 (10), 20-26.

John, Ameriks.,Tanja, Wranik., \& Peter, Salovey. (2009). Emotional intelligence and investor behaviour, Research Foundation Publications, 1-75.

Lennox, R.D., \& Wolfe, R.N. (1984).Revision of the self-monitoring scale, Journal of Personality and Social Psychology, 46(6), 1349-1364.

Lynch, A. (2002). Evolutionary contagion in mental software evolution of intelligence, New Jersey, Lawrence Erlbaum Associates, 289-314.

Oslen, R.A. (2010). Towards a theory of behavioural finance: Implications from the natural science, Qualitative Research in Financial Market, 2(2), 100-128.

Reuven Bar-On. (1997). The Emotional Quotient Inventory (EQ-i): Technical Manual, Toronto, Canada: Multi-Health Systems.

Ricciardi, V. (2006). A research starting point for the new scholar: A unique perspective of behavioural finance. ICFAI Journal of Behavioural Finance, 3(3), 6-23.

Richard, A. Thaler., and Eric, J. Johnson. (1990). Gambling with the house money and trying to break even: The effects of prior outcome on risky choice, Management Science, 36(6), 643-660.

Robbins, Stephen. \& Timothy A, Judge. (2009). Organisational Behaviour. Pearson Education Inc. $13^{\text {th }}$ Ed. ISBN 0136007171.

Salovey, P. \& Mayer, J.D (1990). Emotional Intelligence, Imagination, Cognition and Personality, 9, 185211.

Thomas, Lux. (1995). Herd behaviour, bubbles and crashes, Economic Journal, 105(431), 881-896.
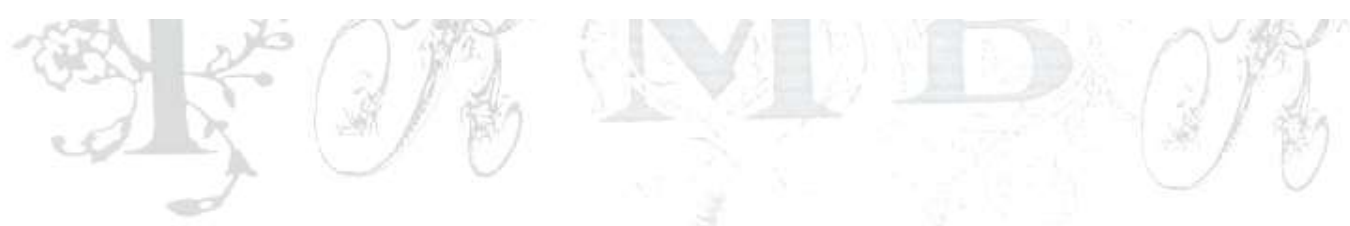